\title{
Research on Sponge Campus Application Based on Low Impact Development Measures--- A Case Study of Wuhan Polytechnic University
}

\author{
Jingjing Liu ${ }^{1, *}$, Haoyu Zhang $^{2}$ \\ ${ }^{1}$ School of Civil Engineering and Architecture, Wuhan Polytechnic University, China \\ ${ }^{2}$ Graduate School of Engineering, Kobe University, Japan
}

\begin{abstract}
In recent years, China has vigorously promoted the construction of sponge cities and achieved good results. The university campus is a relatively independent existence in the city. Due to historical planning and construction reasons, it is easy to accumulate water when the city has a large amount of precipitation. Taking Wuhan Polytechnic University as an example, this paper analyzes the causes of waterlogging on campus from the aspects of urban precipitation, campus planning, rainwater harvesting and utilization, and proposes a series of low-impact development (LID) measures, such as increasing the permeability of paving area, building vegetative ditch, setting up infiltration green belt, and renovating the artificial lake in the school. The author adopted the SWMM model of urban stormwater management developed by the U.S.EPA as a carrier to construct a low-impact rainwater system model, The SWMM model which funded by the US Environmental Protection Agency was used to construct a low-impact development rainwater system model to evaluate the effect of low-impact development measures on ground runoff control.
\end{abstract}

\section{Introduction}

In the past few decades, China has started a rapid urbanization process due to economic prosperity. Rapid urbanization and industrialization have destroyed the balance of the original urban ecological natural system. A large number of vegetation and green landscapes in the city were excavated and replaced by high-rise buildings and hard paved roads. These factors have led to rainwater accumulation cannot be discharged in many cities in China in recent years after heavy rains. In recent years, this phenomenon has attracted the attention of relevant departments in China.

In foreign countries, research on rainwater control and urban flood control system construction started earlier and is more mature. These studies focus on improving and solving the problem of urban stormwater control and rational use. The United States proposed the best management practice (BMP) in the 1970s. This method was originally applied to the use of engineering measures and artificial means to drain flood control [1]. A group of American cities, represented by Chicago, have implemented the idea of BMP by deepening tunnels to introduce rainwater into reservoirs or other waters. However, it has been found in practice that the BMP theory has some defects. It only focuses on water flow path control and has no effect on the source suppression of urban rainwater. So after more than 20 years of research and practice, in the 1990s, the second generation of rainwater control concept, the low impact development (LID) concept was proposed [2]. The method uses a source suppression strategy to control stormwater by improving the operational process of natural water cycle.

The "Sponge City" concept has evolved from the BMP and LID concepts. In October 2014, the Ministry of Housing and Urban-Rural Development of China promulgated the "Technical Guide for Sponge City Construction--Construction of Low Impact Development Rainwater System (Trial)". The guide states: "Sponge city means that the city can be like a sponge and has good 'elasticity' in adapting to environmental changes and coping with natural disasters. When it rains, water storage facility absorbs water, accumulates water, seeps water, and cleans water. When needed, it will 'release' the water and use it. Sponge city construction should follow the principle of ecological priority, combine natural and manual measures, ensure urban drainage and flood prevention, realize the accumulation, penetration and purification of rainwater in urban areas, promote the use of rainwater resources and ecological environment protection[3]."

On April 2, 2015, 16 cities were awarded the first batch of "Sponge City" pilot qualifications, and Wuhan is one of them. Wuhan is a city with a long history and more than one million college students study and live in this city. Many university campuses were built early. At the time of construction, the concept of the sponge campus has not been proposed, and there is a large area of hardened ground on the university campus. In the case

\footnotetext{
* Corresponding author: 36957703@qq.com
} 
of heavy rain, the problem of rainwater runoff cannot be scientifically treated, and the accumulated water in the campus area will affect teachers and students. The transformation of the "sponge campus" on the campus will be a matter of real significance.

\section{Research area overview}

This paper will use Wuhan Polytechnic University as the research object to carry out LID facility layout and effectively control the peak runoff. Wuhan Polytechnic University, founded in 1951, is located in the north of the Third Ring Road in Dongxihu District, Wuhan City, Hubei Province. The school has two campuses, with a school area of nearly 1 million square meters and a school building area of 510,000 square meters. In the two campuses, the Changqing campus was built earlier. The original land area of Changqing Campus is 290,000 square meters. After the annexation of Wuhan Transportation Health School, the area increased to 334,000 square meters. The plan of Changqing Campus is shown in Figure 1.

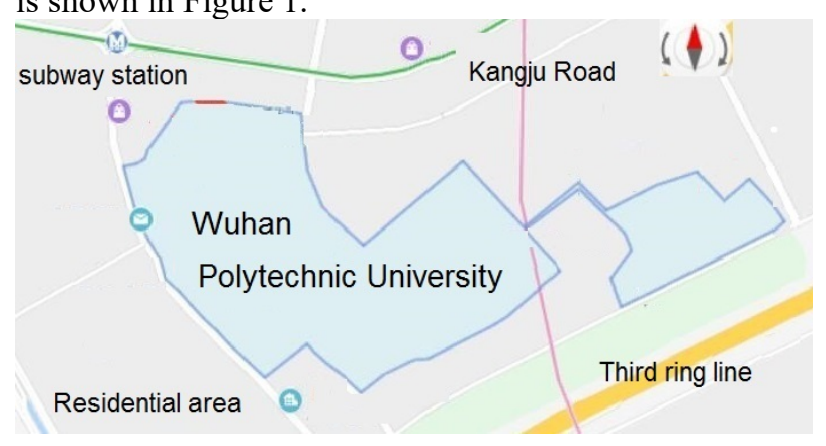

Fig. 1. Plan of Changqing Campus

\section{Status and problems}

Due to the lack of scientific rainwater planning during campus construction, some road sections are prone to water accumulation in rainy days, affecting teachers and students. The main rain and flood problems in the study area are summarized below.

\subsection{The rainfall in Wuhan is unevenly distributed throughout the year.}

Wuhan rainfall distribution has strong seasonality. According to the data of Donghu Hydrological Station, the precipitation of Wuhan in the five years from 2012 to 2016 (as shown in Table 1, 2) is statistically analyzed. It can be seen that most of the precipitation in Wuhan is concentrated from March to July. During this time, the average rainfall value reached more than $100 \mathrm{~mm}$ per month, accounting for more than $60 \%$ of the total annual rainfall. The monthly average precipitation in July reached more than $200 \mathrm{~mm}$. There is less precipitation in autumn and winter. The rainstorm in Wuhan in summer is characterized by a large amount of precipitation in a short period of time. For example, on June 21, 2019, the city's precipitation exceeded $120 \mathrm{~mm} / \mathrm{d}$. When the rainstorm comes, the urban drainage system designed according to the routine is overwhelmed and can easily cause water accumulation.

Table 1. 2012-2016 Wuhan first half of precipitation. (mm)

\begin{tabular}{|c|c|c|c|c|c|c|}
\hline Year & Jan & Feb & Mar & Apr & May & Jun \\
\hline 2012 & 58.2 & 79.3 & 20.7 & 106.3 & 202.6 & 57.2 \\
\hline 2013 & 59.6 & 118.6 & 116.6 & 69.0 & 216.5 & 87.0 \\
\hline 2014 & 95.9 & 20.9 & 72.0 & 84.5 & 201.0 & 141.0 \\
\hline 2015 & 15.6 & 139 & 69.6 & 183.0 & 160.5 & 296.0 \\
\hline 2016 & 41.0 & 63.5 & 237.5 & 127.5 & 154.0 & 170.0 \\
\hline Average & 54.0 & 84.2 & 103.3 & 114.1 & 186.9 & 150.2 \\
\hline
\end{tabular}

Table 2. 2012-2016 Wuhan second half of precipitation (mm)

\begin{tabular}{|c|c|c|c|c|c|c|}
\hline Year & Jul & Aug & Sep & Oct & Nov & Dec \\
\hline 2012 & 109.8 & 132.4 & 40.6 & 52.1 & 50.3 & 20.4 \\
\hline 2013 & 181.0 & 86.7 & 33.0 & 26.0 & 38.0 & 24.5 \\
\hline 2014 & 172.5 & 138.8 & 24.5 & 111.5 & 54.5 & 10.5 \\
\hline 2015 & 124.0 & 5.0 & 22.5 & 35.0 & 62.9 & 46.4 \\
\hline 2016 & 414.5 & 116.5 & 110.0 & 90.5 & 8.0 & 16.5 \\
\hline Average & 200.4 & 95.9 & 46.1 & 63.0 & 42.7 & 23.7 \\
\hline
\end{tabular}

\subsection{Large impervious floor area on campus}

In the process of campus infrastructure construction and design, there is a lack of a rational and scientific guidance on the rain and flood system. Rainwater management is not considered in the design, so that natural rainfall does not scientifically penetrate, retain, accumulate, purify, utilize and discharge. The area of buildings, parking lots, sports fields and roads on campus is 210,000 square meters, accounting for more than $60 \%$ of the total campus area. Large areas of impervious surfaces affect the natural penetration of rainfall. There is a relatively large surface runoff in heavy rain.

\subsection{Campus rainwater drainage system design is unreasonable}

There is a concrete belt between the road green belt and the road. Rain on the road cannot seep into the road green belt. Rainwater can only be discharged directly into the nearby urban drainage system through the sewer line. The campus has a large area, there is a lot of rainwater when it rains. If it is discharged directly, it will bring a great burden to the urban drainage system.

\subsection{Rainwater is not recycled, and waste is large}

The campus rainwater management method only considers the drainage problem, and lacks research on the penetration, accumulation, purification and utilization of rainwater. Rainwater has not been effectively utilized, and rainwater resources are seriously wasted. The rainwater on the roof of the school building is directly discharged to the ground through the PVC pipe. In the rainy weather, the rain on the roof of the buildings in the students and teachers' living quarters is flowing everywhere on the ground, causing great inconvenience to teachers and students. If the rainwater 
resources can be used reasonably, the rainwater will be collected for urban irrigation, cleaning, etc.

\section{Campus low impact development (LID) measures}

The campus is a densely populated area of the city. Combine the construction of sponge city infrastructure with campus landscape design to improve the quality of campus ecological environment, that is, improve the quality of our city's ecological environment. The construction of the sponge campus can enhance the awareness of the school members to save water and protect the environment.

\subsection{Increase the permeability of paving area}

Traditional hard paving materials prevent rainwater from invading the subsurface structure. At the same time, hard paving materials can make rainwater unable to infiltrate, and also block groundwater evaporating from the surface, destroying the circulation of water.

Permeable pavement refers to paving with a reasonable structure using paving materials with excellent water permeability [4]. According to the different characteristics of the materials, mixed permeable asphalt can be used as the surface layer for the main roads in the school. The material is low in cost and higher in strength than permeable concrete, and can be constructed by integral pouring. Water-permeable bricks can be laid on the parking lot ground. Although the price of permeable bricks is high, the permeable bricks can be flexibly spliced and suitable for small-scale paving. Under the permeable material, a filter layer or other drainage ditch should be installed to achieve rapid water seepage and reduce ground runoff.

\subsection{Building vegetative ditch}

Vegetation ditch refers to a surface ditch that is distributed in a strip shape with an inverted V-shaped section and planted vegetation. It Can be set in the green forest on campus. The surface of the vegetative ditch covers the planting soil, on which planting plants to store water. Below the planting layer, there are sand and gravel layers with good water permeability in order to infiltrate excess water. It can effectively reduce the runoff flow rate and purify it on the way to transport rainwater. The plant ditch is inexpensive and can be used as a rainwater transmission control measure in conjunction with many other "sponge body" design measures.

\subsection{Set up infiltration green belt}

The design elevation of the green belt on both sides of the road is lower than the road. The filter device is made of gravel and iron mesh between the sidewalk and the green belt. The surface layer of the greenbelt is planted soil, with planting street trees (Fig. 2). Under the planting soil, coarse sand and gravel are laid as a filter layer. Sidewalk is paved with water-permeable materials, such as permeable paving, grass bricks, anti-corrosion wood, etc. The sidewalk is inclined to the green belt, and the rainwater flow is guided by the height difference, so that the rainwater that cannot be infiltrated in time during heavy rain flows to the green belt.

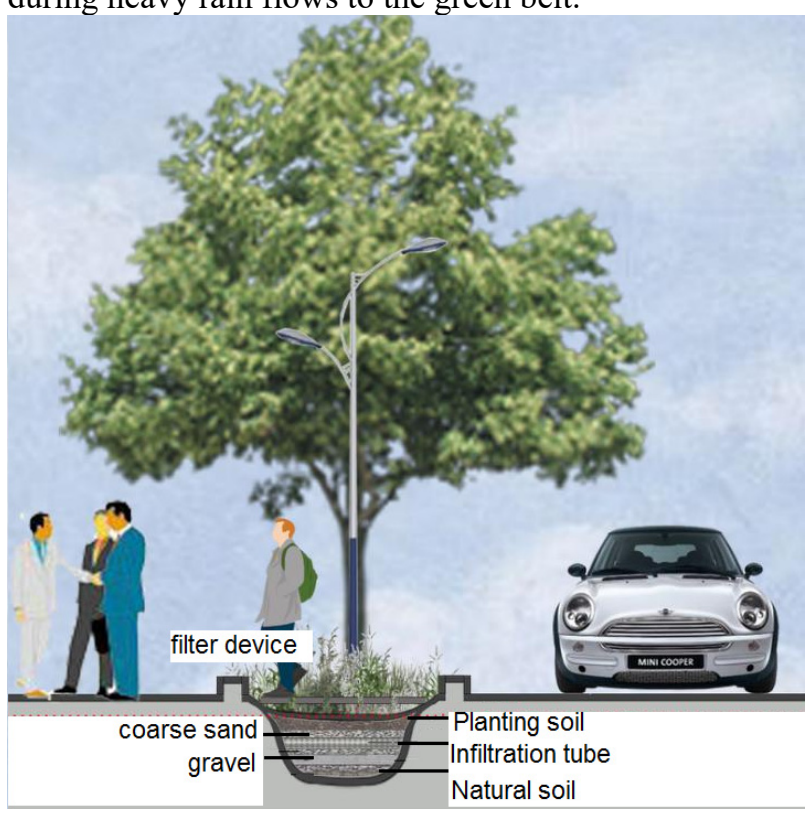

Fig.2. Structure of infiltration green belt

\subsection{Transforming the campus artificial lake into a constructed wetland}

The original artificial lake on the campus is a concrete pond with a water corridor for viewing. Because there is no water cycle with nature, the water quality is poor. In order to enhance the ability of rainwater regulation, the artificial lake was changed into artificial rainwater wetland.

The artificial rainwater wetland only lays concrete in the middle of the wetland, and the bank is designed with a gentle slope. The gravel permeable layer is laid in the lower layer of the gentle slope, and the aquatic plants are planted in the upper layer. The ecological model of artificial facilities, aquatic wet plants and various microorganisms can be used to achieve the function of stagnation, purification and regulation of circulation of rainwater or surface runoff. The wetland can collect and purify the water from the plant ditch and the permeable pavement, and build it into a multi-functional rainwater storage system to improve the ecological water cycle.

\section{SWMM model establishment and LID effect evaluation}

The Storm Water Management Model (SWMM) developed by the US EPA. It has strong applicability, simple operation and comprehensive functions[5]. This article will simulate the effect after the establishment of Low Impact Development (LID) measures on campus using SWMM. 


\subsection{SWMM model establishment}

\subsubsection{Sub-water area parameter}

The parameters that need to be input for each Sub-water area are: Sub-area, Width, Imperviousness (\%), Slope (\%), Permeable Area and Impervious Area Confluence Manning coefficient (N-imperv and N-perv), waterpermeable surface and impervious surface water storage capacity (Des-imperv and Des-perv), Non-aggregated water impervious area ratio( Zero-Imperv ,\%) and the infiltration model of permeable surface. Among them, Sub-area, Width, Imperviousness, Slope are directly calculated by Arc GIS based on the basic data of the study area. The Manning coefficient and Des-imperv and Des-perv parameter values are determined according to typical values in the model manual.

\subsubsection{Hydraulic parameters}

The hydraulic parameters mainly describe the characteristics of the drainage network, including the pipeline Manning coefficient, pipeline attribute parameters and node attribute parameters. The pipe attribute is valued according to the pipe network design data. The pipe length is obtained by the model automatic measurement tool. The Manning coefficient of the pipeline is obtained according to the manual experience value, which is 0.013 . The property of the inspection well node in the area is directly obtained from the pipe network design data.

\subsubsection{Soil permeability parameter}

The rainfall infiltration process was simulated by the Horton infiltration model. The parameters to be input by the model mainly include the maximum infiltration rate, the minimum infiltration rate and the attenuation coefficient. The maximum infiltration rate is $220 \mathrm{~mm} / \mathrm{h}$, and the minimum infiltration rate is $1.5 \times 10-5 \mathrm{~cm} / \mathrm{s}$.

\subsubsection{LID parameter}

In SWMM, the LID controls module has a number of sponge city options to choose from The LID measures adopted in this campus include permeable paving, vegetative swale, infiltration trench, and rain garden. The arrangement of the LID facilities in the site is to allocate the pre-defined facilities to the subset catchment area according to a certain proportion, as shown in Figure 3.

\subsection{SWMM model evaluation result}

The north-south height difference of Changqing Campus is no more than $1 \mathrm{~m}$, and the south is lower. There are two main outlets in the study area. This model evaluates the flow change of the No.1 outlet. The rainstorm period of 3 years and the rainfall duration of $120 \mathrm{~mm}$ were simulated. When the LID measure is not set, the runoff control rate is $42.12 \%$, and the No. 1 drain flow rate is $520 \mathrm{l} / \mathrm{s}$. After the LID measures were set, the runoff control rate was $72.25 \%$, and the No. 1 drain flow decreased by $25 \%$.

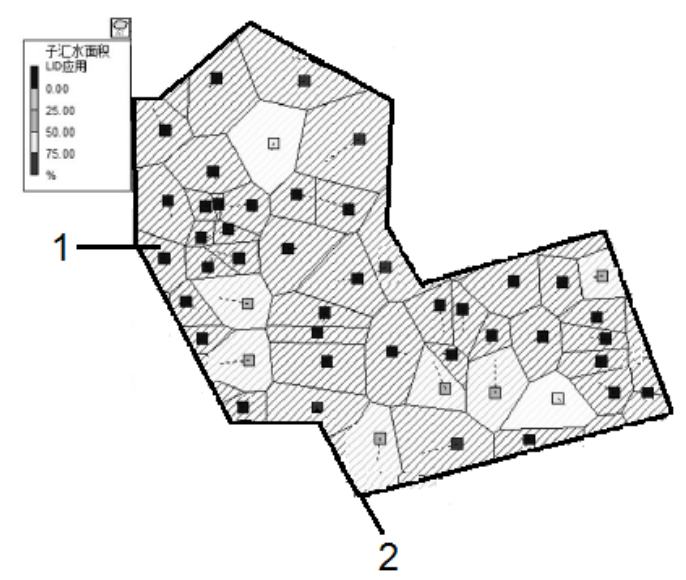

Fig.3. LID facility allocation map

\section{Conclusion}

This study provides a campus reconstruction plan for Wuhan Polytechnic University based on the LID concept. The low-impact development concept combines architecture and ecological civilization construction, which is a technical method to create a benign hydrological cycle. LID plays a significant role in controlling rainwater at the source, reusing rainwater resources, and reducing runoff. The construction of the sponge campus has scientifically realized the penetration, storage, purification and discharge of water resources.

\section{References}

1. W. Che, X.B. Chou, Urban ecological rainwater management system. Water and Wastewater Engineering,7:17-23 (2014)

2. L.M. Ahiablame ,B.A.Engel,et al. Effectiveness of low impact development practices: literature review and suggestions for future research. Water, Air\& Soil Pollution,223(7): 4253-4273 (2012)

3. C.W.Hu. Sponge city reconstructs urban water ecology.Ecological Economy,31(7) :10-13(2014)

4. Z.Y.Chen, Planning and Design of Municipal Road under the Guidance of Sponge City Concept.China Construction, 12 :118-119 (2017)

5. C.P.Song,H.C.Wang,D.S.Tang. SWMM research progress and devolopment trend. China Water \& Wastewater,16 :16-20(2015). 